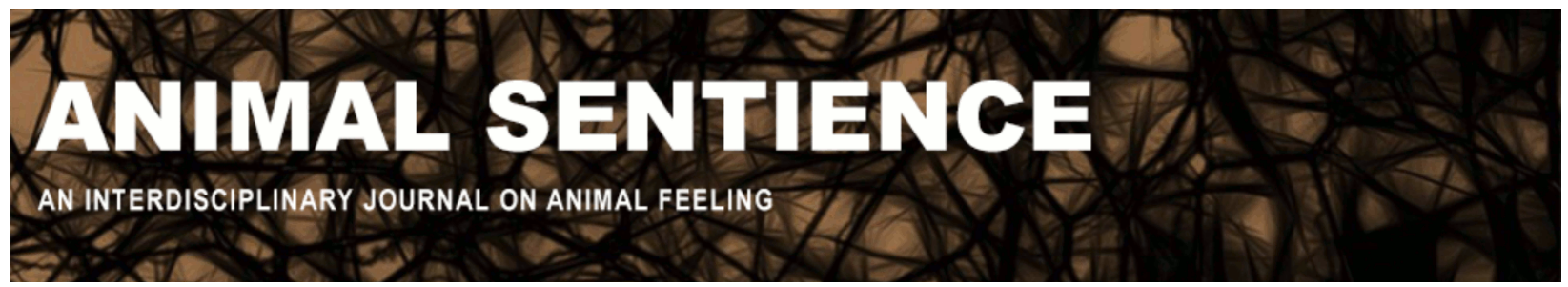

Kuperus, Gerard (2018) Continuum and temporality. Animal Sentience 20(15) DOI: $10.51291 / 2377-7478.1303$

Date of submission: 2018-02-01

Date of acceptance: 2018-02-11

(c) (i)




\title{
Continuum and temporality
}

Commentary on Peña-Guzmán on Animal Suicide

\author{
Gerard Kuperus \\ Department of Philosophy \\ University of San Francisco
}

\begin{abstract}
I fully support the continuum proposed in the target article and argue along the same lines that we should be suspicious of drawing any strict borders between human and non-human animals. Since we can say very little with absolute certainty about human intentions regarding suicide, we have no certainty about the intentions of non-human animals. Although I am very sympathetic to Peña-Guzmán's overall argument, I suggest that time could be taken into consideration as well.
\end{abstract}

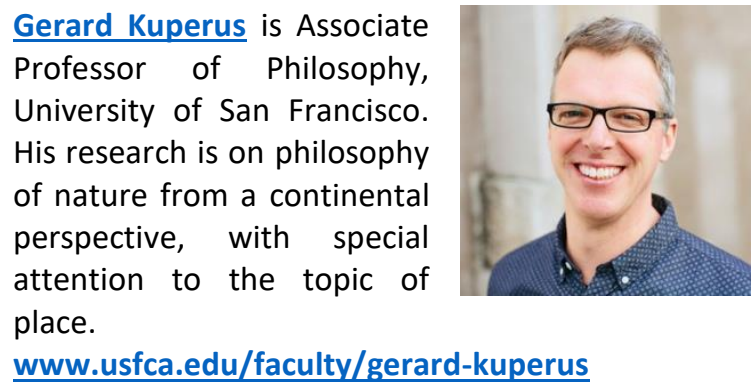

Whenever we end up comparing human and non-human animals, we typically end up arguing for or against "giving" animals a seemingly positive attribute, such as intelligence, feelings, making decisions, etc. One interesting aspect of Peña-Guzmán's (2017) target article is that he focuses on a very negative aspect of human life, suicide, and makes a strong case that other animals might be able to decide to end their lives.

A lot is at stake here: reflexive subjectivity, free will, and awareness of death (discussed in the first part) on the side of the non-human animal, as well as the human animal. For, what do we really understand about suicide? We probably all know at least one person who has attempted or committed suicide. We understand that they are suffering tremendously, and we feel compassion, but I cannot say that I fully understand their reasons for wanting to end their lives. Furthermore, do they fully understand it themselves? Did they make a rational decision? Do they understand the consequences of their act? What is their intention? In short, what exactly is human suicide ${ }^{1}$ When it comes to non-human animals, with whom we have trouble

\footnotetext{
${ }^{1}$ As an example of decision-making regarding suicide, we can take the 2006 documentary The Bridge, which tells the story of people who commit suicide by jumping off the Golden Gate Bridge. Several people are filmed jumping off the bridge, toward their death. It is extraordinary how casual this act appears to be. One moment they stand on the edge, the next they step off, as if they get off a bus on the way to work. A few moments later, they hit the water and die instantly. One person who survived is interviewed and shares that
} 
communicating, all these questions become even harder to answer. Yet, when I observe animals in confinement such as in zoos, "Concentrated Animal Feeding Operations," or laboratories, I quickly ascertain (on what could be considered an "instinctual level") that these animals (1) do not live a life worth living and (2) would be better off dead. Whether they themselves think about it in a similar way is harder to determine. ${ }^{2}$

Peña-Guzmán engages with and disputes convincingly the different arguments that deny animal suicide. One aspect I missed in his discussion is an engagement with time. As Nietzsche (1989, "Second Essay") argues, it is our inability to forget the past that makes us feel guilt and that torments us. In relation to suicide, we can say that many mental health issues that result in suicide are related to traumatic stress disorder. If we could only forget the past! If an animal forgets the past - I am not suggesting this is the case - a similar kind of trauma would not be possible. Committing suicide because of a traumatic experience (loss of freedom, losing one's offspring soon after they are born, living in a world of feces, etc.) is not a possibility if they do not remember it. On the other hand, if we think about the future, Heidegger (famously) determines the essence of our being as time (and rejects the possibility that non-human animals can relate to time "as such") (see Kuperus 2007). The fundamental attunement of anxiety describes the situation in which one relates to one's death (or "the nothing") and recognizes one's own finitude. I recognize myself as time, time that is ticking away (Heidegger 1962). Everyone has experienced this anxiety, and it is this recognition of our own mortality that makes the decision to commit suicide such a serious and radical act. This returns us to Peña-Guzmán's discussion of the awareness of death.

Whether other animals are able to experience Heideggerian anxiety over their own finitude is an interesting academic question, yet I would also emphasize that the question is coming out of a mindset that is suspicious of animals' abilities. All the arguments against the possibility of animal suicide are representative of the Cartesian model that has dominated our thinking about animals. This model presents us with animals as mere machines that, for example, might kill themselves instinctually, without any real agency, subjectivity, free will, awareness of

the moment he jumped he changed his mind and wanted to live. He made sure to land feet first and miraculously survived (apparently with the aid of a black seal, which he explains as a sign from God).

${ }^{2}$ We could be making a horrible mistake if we simply acted on our assumption that animals do not have the ability to wish to end their lives. What do we really do to an animal when we lock it up, for example? A book such as What a Fish Knows: The Inner Lives of our Underwater Cousins (Balcombe 2016a,b) truly challenges our sense that fishes (even goldfishes) lack intelligence. On a more personal level, this winter break, before reading Peña-Guzmán's essay, we had some non-human visitors in our house: five fishes. They came from the (vacationing) household of my son's best friend. The fish (two goldfishes and three guppies) were in a nice aquarium, with equipment such as a filter, lights, and heater, as well as a little (fake) submarine, fake plants, and some (real!) rocks on the bottom. The backside had a print of a coral reef glued to it. The fish were in a clean (albeit largely artificial) environment, well-fed, and living without the threat of predators (assuming they were not going to eat one another). Yet, as soon as they were in our home, I started to wonder about their existence. Whether fish have rational capacities or live purely instinctually (or whatever we want to call their natural drives), there is no doubt about this simple fact: these fish are locked up, are unable to explore or act on their natural instincts, and it seems that the only thing they can look forward to is their daily feeding (which they were obviously rather obsessed about). I remembered the goldfish we had in a bowl when I was young. They never lived very long. Was that because we did not take good enough care of them, because their environment was not healthy, or was it possible that they somehow ended their own lives? The very fact that, as Peña-Guzmán shows, we cannot answer this question clearly, should make us think twice before locking up a fish or any other animal. 
death or intentionality. I really appreciate the target article's approach regarding a continuum. Why indeed would non-human animals be so radically different? Why would a human suicide be a rational, free choice, with clear intentions and an understanding of the consequences of the act - all of this can be brought into question, as is pointed out - whereas a non-human animal lacks all of these? We should shift away from the paradigm of the Cartesian abyss of difference between human rationality and animal instincts. This means, first of all, questioning the idea of human exceptionalism. We are part of nature, just one of its many parts - nothing too special. As Spinoza (1992) points out, humans are mistaken when they think that they are free by virtue of their ability to be aware of wishes and desires. ${ }^{3}$ Who we are, what we do, and omit to do, is determined through forces that are outside our control. We are mistaken when we think we freely choose, whether we are choosing to buy a gadget, which beer or wine to drink (or not to drink at all), or whether to end or not end our lives. We are also endowed with a conscience and have learned that ending our lives is a sin. If animals are not bothered by a conscience (as we mostly assume), could we perhaps even suggest that suicide may be more common in the non-human animal?

In closing, I want to thank Peña-Guzmán for his marvelous work on the issue of animal suicide. It is a clear engagement with the issue and should make all readers seriously reconsider the question.

\section{References}

Balcombe, J. (2016a) In praise of fishes: Précis of What a fish knows (Balcombe 2016). Animal Sentience 8(1).

Balcombe, J. (2016b) What a fish knows: The inner lives of our underwater cousins. New York: Farrar, Straus \& Giroux.

Heidegger, M. (1962) Being and time. New York: Harper.

Kuperus, G. (2007) Heidegger and animality. In: Painter, C., and Lotz, C. (Eds.), Phenomenology and the non-human animal at the limits of experience. Dordrecht: Springer.

Nietzsche, F. W. (1989) On the genealogy of morals: Ecce homo. New York: Vintage.

Peña-Guzmán, D. (2017) Can nonhuman animals commit suicide? Animal Sentience 20(1).

Spinoza, B. (1992) The ethics: Treatise on the emendation of the intellect; Selected letters. Indianapolis: Hackett.

\footnotetext{
${ }^{3}$ Spinoza (1992) writes that "men think themselves free inasmuch as they are conscious of their volitions and desires, and never even dream, in their ignorance, of the causes which have disposed them so to wish and desire" (Appendix Part I).
} 